A AUTORA

Regina Aparecida de Oliveira

Professora do Ensino Fundamental na Escola

Estadual Antônio de Oliveira Bueno Filho,

Araraquara, SP.

\title{
JORNAL, JOGOS E BRINCADEIRAS
}

\author{
Todos os textos como pretexto para \\ aprender a ler o mundo e transformá-lo
}

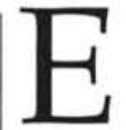

m 1985, trabalhei com um projeto de alfabetização de adultos, patrocinado pelo Sindicato dos Fornecedores de Cana de Araraquara. As aulas eram dadas aos sábados, para funcionários da usina.

Com o apoio da prefeitura local, estendeu-se para o período noturno e foi desenvolvido por mais dois anos. Os alunos tinham entre quinze e sessenta anos, o método era trabalhar a partir da experiência dos alunos. Os textos eram escolhidos de acordo com a vivência dos alunos e a participação era intensa. A alfabetização de crianças e de adultos envolveu-me em situações práticas que me deram confiança neste método de trabalho.

Em 1997, trabalhei com a primeira série do ensino fundamental. Usava alguns jornais como material de trabalho e, principalmente, as propagandas de supermercados. Usávamos os rótulos das embalagens para trabalhar as disciplinas de forma multidisciplinar.
Notava que as crianças chegavam empolgados na sala de aula, sempre com alguma novidade. Elas traziam notícias, histórias, músicas, relatos do cotidiano delas. Percebi que o jornal exercia sobre as crianças um certo fascínio: as letras, as fotos coloridas, certas notícias.

Deixava os jornais dentro de uma caixa para as consultas e notava que eles os desfolhavam. Procuravam no jornal algo que lhes chamasse a atenção. Assim, dediquei-me ao trabalho de alfabetização com jornal, não usando o livro didático. Diariamente recebo 40 exemplares do jornal Tribuna Impressa, de Araraquara - SP.

$\mathrm{O}$ objetivo da experiência foi fornecer oportunidades para que as crianças conheçam verdadeiramente aquilo que as cerca. Isto é, levar a criança a perceber a relação entre ela e o mundo que a cerca a partir do processo de alfabetização. Propiciar a troca de informações, apresentação e discussão de idéias. Preparar para a construção individual e coletiva de textos. Através da 
leitura e escritura, a criança aprende a identificar dentro e fora do contexto do jornal os vários suportes dos textos. Por fim, pretendo desenvolver a observação, o senso crítico e a cidadania.

\section{DESENVOLVIMENTO DAS AÇÕES}

No trabalho com o jornal diário, desenvolvo algumas estratégias para envolver os alunos. Procuro familiarizá-los com os elementos do alfabeto. A partir da identificação das letras, peço às crianças que recortem e colem as letras em um caderno ao qual denomino caderno alfabético. Posteriormente, elas associam as palavras às letras do caderno alfabético, anotando-as conforme a ordem alfabética.

Fazemos a leitura do jornal, diariamente. Através de escolha feita pela classe, selecionamos a notícia a ser trabalhada. Procuro discutir o conteúdo da informação sem esquecer que reconhecer as letras e compreender os seus significados é de fato a verdadeira alfabetização. De acordo com a notícia escolhida, sentados todos em círculo no chão, com o alfabeto móvel, os alunos escrevem uma frase. Aquele que possui mais dificuldade o coleguinha ao lado ajuda. Fazemos a discussão deste texto escolhido. Como todos querem falar ao mesmo tempo, organizamos para que cada um tenha a sua vez. Cada dia uma criança se coloca como locutor e organiza quem fala, havendo uma sequiência. É interessante como elas vivenciam essas notícias, muitas vezes associando-as a fatos do seu próprio cotidiano.

As crianças também gostam do jornal porque traz notícias do seu bairro. São notícias da cidade que elas conhecem. Isto é importante principalmente para a primeira série, que é muito apegada ao concreto.

As crianças copiam a frase do jornal no caderno e, para melhor fixação da notícia, uso símbolos embaixo das frases. Depois dessa seqüência, retiramos da notícia a palavra-chave do texto jornalístico. O caderno alfabético todo dia é usado e notase sua importância, pois a criança associa a palavra à letra correspondente. Todo dia é uma nova descoberta.

As charges são as mais apreciadas pelas crianças. No começo do ano, eles eram dependentes quanto à hora de recortar, colar. Durante os meses seguintes foi se criando maior autonomia, agora já recebem o jornal e vão procurando as charges, recortando e já sabem o local do jornal onde as encontram. Criou-se um ritmo de trabalho muito bom. Através das charges, criam novos textos e desenhos.

As várias modalidades de esportes também são identificadas pelas crianças. Quando trabalhamos com as notícias da Copa do Mundo, as crianças escreviam nomes dos jogadores, usando o alfabeto móvel e o caderno. Trabalhamos com a localização, costumes e vestimentas de alguns países. As tabelas e gráficos foram utilizados para leitura e sistematização da informação.

As crianças vão às compras é um dos temas do nosso trabalho em Matemática. Temos uma prateleira na sala de aula na qual ficam expostas várias embalagens. É o nosso mercadinho, e há sempre um aluno como caixa. 
As crianças recortam propaganda de supermercado e semanalmente fazem a tabela de preços, comparando-os à tabela de produtos que são encontrados no jornal. Com isso já estão aprendendo a escrever nomes de frutas, verduras, entre outros gêneros alimentícios.

Outro tema de trabalho foi chamado de: conhecendo meu signo. A data do aniversário fica marcada também pelos signos. Para saber o signo as crianças aprendem a guardar a data do seu nascimento. Montamos um painel na sala, para trabalharmos com o gráfico do mês dos aniversariantes. Conseqüentemente trabalhamos as frações, pois as crianças brincam com o bolo de aniversário, feito de argila ou massa de farinha, contam quantos são os aniversariantes de cada mês e vão cortando o bolo.

Para trabalhar com os signos, foram recortados pedaços de madeira: em umas pintei os símbolos de cada signo, e em outras os nomes dos signos. Todos sentados, as peças são embaralhadas no chão. Os alunos pegam o desenho e procuram a palavra que representa o signo.

Outro tipo de jogo foi chamado de: vamos adivinhar quem é. Mostra-se o símbolo ou a palavra e as crianças dizem qual o signo. Dão-se todas as características do aluno, e pede-se para se dizer quem é.

A lista telefônica também vira material para o nosso trabalho. Com os números de telefones que aparecem no jornal, passei a usar a lista telefônica para que as crianças localizem os nomes em ordem alfabética.

As receitas trazidas pelo jornal são utilizadas em sala de aula. Faz-se a leitura para a primeira série fica mais fácil transformar os ingredientes e medidas em símbolos - e tudo é copiado no caderno de receitas. As crianças também trazem de casa receitas que a mãe ensina. Usamos muitas das receitas, elas são feitas junto com as crianças.
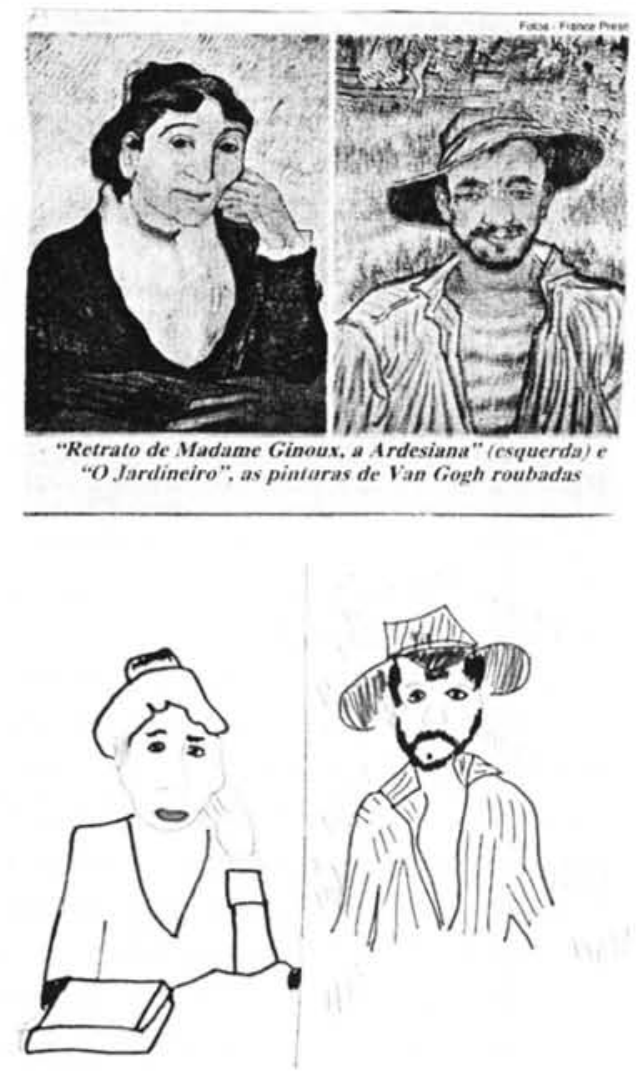

A aluna Juliana faz sua versão das obras de Van Gogh.

No jornal encontramos ainda, na maioria das vezes, obras de pintores regionais e também de pintores renomados como Pablo Picasso, Van Gogh etc. São notícias diversas sobre obras que foram roubadas, vendidas, ou de eventos e exposições. Através dela as crianças passam a conhecer os pintores. Depois, as crianças são incentivadas a criar sua própria obra a partir das reproduções das obras dos pintores que aparecem no jornal.

Como a televisão é um meio de comunicação bastante presente e as crianças 
assistem às novelas, peço, então, que contem, em sala de aula, os capítulos das novelas que mais chamam a sua atenção. É um momento de bate-papo com as crianças, e percebo como elas são atenciosas nos pequenos detalhes. São críticas.

Elas também adoram histórias em quadrinhos, lemos as histórias e solicito que observem atentamente os desenhos. Converso com eles sobre a história apresentada pelos quadrinhos. Faço perguntas sobre o que está acontecendo em cada quadro. As histórias em quadrinhos, as dramatizações, os desenhos são estratégias que propiciam ao aluno noção de sequiência e variedade de vocabulário, levando-os à produção de texto.

Os vídeos de desenhos animados divulgados pelo jornal também servem para o nosso trabalho. O meu objetivo é envolver as crianças em um mundo de fantasias, trabalhando o imaginário e também o real. Ao assistirem ao filme, elas comparam, identificam e discutem de acordo com as situações que a realidade lhes oferece. As crianças assistem ao filme ou ao desenho divulgado pelo jornal, participam de forma atuante, analisando, ilustrando, dando sequiência às histórias.

\section{As crianças fazem comparações entre o texto jornalístico e o do desenho, faço perguntas para orientar e verificar suas atitudes.}

Logo após, a classe é dividida em grupos para avaliarmos os resultados do trabalho feito. São distribuídos cartões com palavras, um para cada grupo. É preciso relacionar o cartão ao filme, ao desenho, ao jornal. Cada grupo relata em que momento apareceu tal palavra ou frase. Eles adoram essas adivinhações e a localização do momento em que elas se passam.

Outro tipo de atividade com o vídeo que proponho é que cada grupo desenhe em uma folha uma cena que apareceu e os outros grupos tentam adivinhar em qual filme e em que sequiência estava. Este tipo de atividade motiva bastante as crianças, criase um ambiente de competição entre elas, todos os grupos querem acertar e torcem.

Dado os resultados positivos que tenho alcançado, resolvi, usar além do jornal, brincadeiras do cotidiano das crianças.

Com as figurinhas que as crianças colecionam, fizemos um painel em madeira. Esse painel ocupa um bom espaço da sala. Nele as crianças colam figurinhas de chicletes, de balas. Não existe um dia pré-fixado para a colagem. Elas mesmas trazem de casa, pregam no painel e escrevem na frente o nome da personagem ou objeto retratado. Este foi mais um meio que encontrei para trabalhar com elas a alfabetização.

Também usamos o tazoo - figurinhas que vêem nos pacotes de "salgadinhos" - para trabalhar Matemática. Fiz um cartaz dividido por colunas. Cada tazoo traz um número de pontos. São colocados nas colunas de acordo com o número, trabalhando as cores, seqüência, ordem. Com as mesmas cores trabalhamos a adição. Se invertê-lo na coluna é subtração. Dá para se trabalhar as quatro operações, tabelas, gráficos.

Com as bolinhas de gude ao mesmo tempo em que as crianças brincam, aprendem a adicionar e subtrair, de acordo com o jogo proposto. Não são só os meninos que jogam, a participação é de todos. 


\section{AVALIAÇÃO DOS RESULTADOS}

É um trabalho a partir do qual os alunos criam e participam o tempo todo. A observação contínua, as discussões orais surgem, e as tarefas individuais e em grupos evidenciam os avanços dos alunos.

Vejo como a alfabetização com o jornal trouxe, além de uma aprendizagem mais lúdica, o manuseio da informação, tão importante para nossa vida hoje. As atividades com brincadeiras do cotidiano da criança mostram avanços e retomam algumas brincadeiras tradicionais como: jogar bolinhas de gude, amarelinha, figurinhas etc.

A própria tecnologia de comunicação (televisão, rádio, jornal) oferece às crianças oportunidades e os meus alunos de escola pública possuem os mesmos direitos em desfrutá-las que outros. Como professora mediadora dessas crianças acredito que se possa resgatar a imagem da Escola pública. $\mathrm{O}$ que passo para os meus alunos é que os trabalhos desenvolvidos são exercidos com cooperação e autonomia para torná-los cidadãos com consciência crítica.
Resumo: Professora do ensino fundamental de escola pública do municipio de Araraquara SP conta o trabalho de alfabetização que desenvolve com seus alunos, tendo como materiais didáticos o jornal diário da cidade $e$ suas diferentes seçōes, receitas de culinária, jogos e brincadeiras infantis. A autora descreve como desenvolve cada etapa do trabalho, o envolvimento das crianças e faz, ao final, a avaliação de sua proposta.

Palavras-chave: jornal, sala de aula, alfabetização, brincadeiras infantis, cidadania, jogos, leitura
(Newspaper and games)

Abstract: A public elementary school teacher from Araraquara (SP) talks about the literacy work she does with her students using the city's daily newspaper and its different sections, recipes, and children's games as her teaching resource materials. The author describes how she carries out each stage of the work, the children's involvement, and, at the end, she evaluates her proposal.

Key words: newspaper, classroom, literacy, children's games, citizenship, games, reading 